D.O.I.: $10.3895 / \mathrm{S} 1808-04482010000100011$

\title{
AVALIAÇÃO DE PERFIS SÔNICOS SINTÉTICOS EM POÇOS DE PETRÓLEO PERFURADOS NAS UNIDADES GEOLÓGICAS PERTENCENTES A BACIA SEDIMENTAR SERGIPE-ALAGOAS
}

\section{EVALUATION OF SYNTHETIC SONIC PROFILES IN WELLS OF OIL PERFORATEED IN THE GEOLOGIC UNITS OF BASIN SEDIMENTARY SERGIPE-ALAGOAS}

\author{
Suzana Leitão Russo ${ }^{1}$; Maria Emilia Camargo ${ }^{2}$; Vitor Hugo Simon ${ }^{3}$ \\ ${ }^{1}$ Universidade Federal de Sergipe - UFS - São Cristóvão - Brasil \\ suzanarusso@ufs.br \\ ${ }^{2}$ Universidade de Caxias do Sul - UCS - Caxias do Sul - Brasil \\ kamargo@terra.com.br \\ ${ }^{3}$ PETROBRAS -Aracaju - Brasil \\ vhsimo@petrobras.com.br
}

\begin{abstract}
Resumo
O perfil sônico é utilizado, principalmente em poços pioneiros, que recebem maiores investimentos para aquisição de dados, pois esses poços servem como referência para analisar o potencial petrolífero da área. Para poços considerados de explotação, normalmente não são corridas as ferramentas sônicas por motivos econômicos, principalmente nos tempos de preço de petróleo baixo. Como não é viável economicamente fazer uma aquisição do perfil sônico, na grande maioria dos poços antigos, principalmente em decorrência da parada da produção do óleo, deve-se recorrer a outros meios para solucionar o problema. Uma das maneiras é utilizar métodos estatísticos que gerem um perfil sônico, dito sintético, para estabelecer estimativas das velocidades sísmicas das rochas ao longo dos poços. Assim, esse trabalho visa comparar modelos encontrados, utilizando-se como variável regressora a variável DT e variáveis explicativas as variáveis RHOB, GR, DCali, PROF dos perfis sônicos sintéticos em poços de petróleo perfurados nas unidades geológicas pertencentes a Bacia Sedimentar Sergipe-Alagoas e que estejam dentro dos padrões de qualidade necessários. O software utilizado foi o SAS® Enterprise Guide 4.
\end{abstract}

Palavras-chave: perfil sônico sintético; regressão múltipla; teste de cohrane-orcutt.

\section{Introdução}

O perfil sônico é utilizado, principalmente em poços pioneiros, que recebem maiores investimentos para aquisição de dados, pois esses poços servem como referência para analisar o potencial petrolífero da área. Já para poços considerados de explotação, normalmente não são 
corridas as ferramentas sônicas por motivos econômicos, principalmente nos tempos de preço de petróleo baixo. O perfil normalmente utilizado para avaliar a porosidade é o perfil de densidade.

Com o avanço da tecnologia e preço de petróleo alto são feitos investimentos em aquisições de sísmica 3D em locais onde não foram feitas aquisições de perfis sônicos, tão necessários para uma perfeita amarração da interpretação sísmica, que é feita em tempo, com as informações de poços que estão em profundidade. Portanto, como não é viável economicamente fazer uma aquisição do perfil sônico, na grande maioria dos poços antigos, principalmente em decorrência da parada da produção do óleo, para contornar a falta de informação, deve-se recorrer a outros meios para solucionar o problema. Uma das maneiras é, utilizar métodos estatísticos que gerem um perfil sônico, dito sintético, para estabelecer estimativas das velocidades sísmicas das rochas ao longo dos poços.

Pretende-se com esse trabalho avaliar a construção de modelos gerados de perfis sônicos sintéticos em poços de petróleo perfurados nas unidades geológicas pertencentes a Bacia Sedimentar Sergipe Alagoas, permitindo a geólogos e geofísicos obterem informações que venham aumentar a qualidade e a confiabilidade dos perfis sônicos sintéticos gerados, dando subsídios do ponto de vista da sua adequabilidade para ser usado como informação geológica, nas interpretações e processamento geofísico, nas áreas cujos poços não dispõem do perfil sônico registrado.

\section{Revisão teórica}

\subsection{Prospecção de petróleo}

\subsubsection{Método sísmico}

Segundo Thomas (2001) o método sísmico de reflexão é o método de prospecção utilizado atualmente na indústria do petróleo, pois fornece alta definição das feições geológicas em subsuperfície propícias à acumulação de hidrocarbonetos, a um custo relativamente baixo. Mais de 90\% dos investimentos em prospecção são aplicados em sísmica de reflexão. Os produtos finais são, entre outros, imagens das estruturas e camadas geológicas em subsuperfície, apresentadas sob as mais diversas formas, que são disponibilizadas para o trabalho dos intérpretes.

O levantamento sísmico inicia-se com a geração de ondas elásticas, através de fontes artificiais, que se propagam pelo interior da Terra, onde são refletidas e refratadas nas interfaces que separam de diferentes constituições petrofísicas, e retornam à superfície, onde são captadas por sofisticados equipamentos de registro.

Como a sísmica de reflexão responde somente ao contraste de impedância das rochas, é possível simular a resposta sísmica de um pacote sedimentar, ou traço sísmico (sismograma sintético) a partir do conhecimento de velocidades e densidades das rochas que o compõe e da 
fonte. Multiplicando-se as velocidades pelas densidades, obtém-se um perfil em profundidade das impedâncias acústicas. A quantidade de energia que é refletida em cada interface é dada pelo coeficiente de reflexão que, para incidência normal, é calculada pela seguinte relação (THOMAS, 2001):

$$
R=\frac{I_{2}-I_{1}}{I_{2}+I_{1}} \quad \text { e } \quad T=1-R
$$

onde: $\mathrm{R}=$ coeficiente de reflexão;

$\mathrm{T}=$ coeficiente de transmissão;

$I_{2}=$ impedância da camada inferior;

$I_{1}=$ impedância da camada superior.

Thomas (2001) comenta que a partir do conhecimento da coluna sedimentar (Figura 1A) obtida na perfuração de um poço, obtém-se as impedâncias acústicas (Figura 1B), das quais calculase a função reflexiva (Figura 1C), utilizando a equação (1) em cada uma das interfaces. Nesta função, cada coeficiente vai refletir para a superfície a mesma assinatura da fonte gerada no ponto de tiro, mantendo as mesmas relações de amplitude e polaridade. Através da Figura 1D vê-se o mecanismo de formação do traço sísmico. Note que a resposta sísmica final para uma seqüência sedimentar consiste no somatório das reflexões individuais de cada interface (Figura 1E). Neste processo perde-se a resolução vertical, pois as reflexões de topo e base das camadas tendem a interferir-se mutuamente. Esta perda de resolução depende basicamente do conteúdo de freqüências da assinatura da fonte, e para levantamentos convencionais a resolução sísmica vertical é da ordem de 10-15 metros.

Figura 1 - Exemplo ilustrativo de um sismograma sintético. (A) coluna sedimentar. (B) impedância acústicas. (C) função refletividade. (D) reflexões individuais de cada interface. (E) traço sintético final

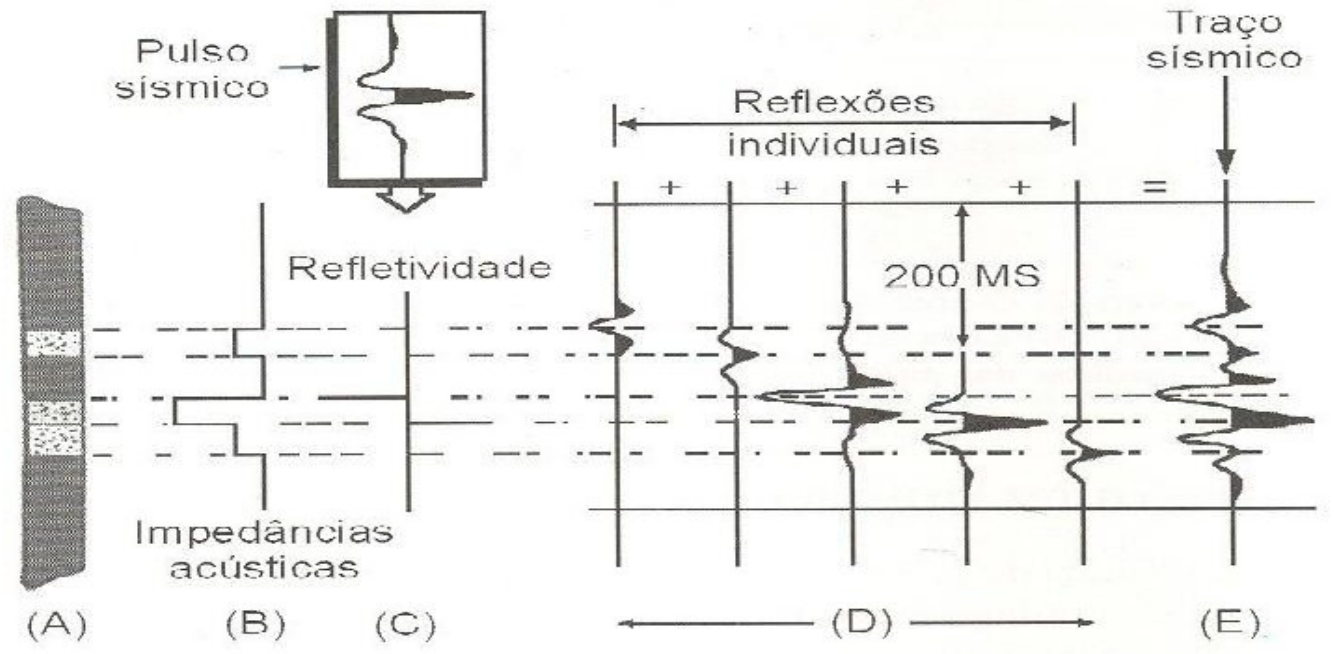


A principal importância do sismograma sintético é correlacionar os dados de poços, que estão representados no domínio do espaço com os eventos que aparecem nas seções sísmicas que estão no domínio do tempo.

\subsubsection{Conceitos básicos}

De acordo com Vasquez (1999), como as propriedades das rochas afetam as velocidades sísmicas que são calculadas através do perfil sônico:

Porosidade - É a principal propriedade física que caracteriza o reservatório, determinada a partir dos dados de perfil sônico, perfil de densidade e perfil de nêutrons, também pode ser medida em laboratório diretamente de amostras de rochas. O aumento na porosidade da rocha provoca um decréscimo na velocidade de propagação das ondas sísmicas.

Composição - O conteúdo litológico (mineralógico) ou litológico da rocha - afeta a velocidade sônica. Cimentos carbonáticos e quartzosos originam velocidades mais elevadas que cimentos argilosos. A presença de argila na rocha é um dos fatores junto com a porosidade que mais influencia a resposta das velocidades sônicas.

Saturação do fluído - Estudos e rochas secas mostram que a saturação parcial de um fluido causa um decréscimo na velocidade da onda compressional (velocidade sônica). Os tipos de fluido contido nos poros de uma rocha influenciam a velocidade devido à compressibilidade do fluido.

Densidade - Gardner et ali (1974) mostrou que a velocidade cresce com o aumento da densidade esta está diretamente ligada à composição mineralógica da rocha e sua porosidade.

\subsection{Modelo de regressão}

A análise de regressão consiste em um método de modelagem que avalia a relação entre uma variável dependente contínua $Y$ e uma ou mais variáveis contínuas independentes $X_{1}, X_{2} \ldots, X_{k}$. O objetivo da análise de regressão é identificar a função que descreve, da melhor forma, a relação entre essas variáveis para que se possa prever que valor a variável dependente vai assumir quando forem atribuídos valores para a variável independente (RAGSDALE, 2001; SUBRAMANIAN et al 2007). 


\subsubsection{O modelo de regressão linear simples (MRLS)}

Conforme Charnet et al (1999), seja $Y$ uma variável aleatória de interesse, muitas vezes denominada variável resposta, e $X$ uma variável aleatória denominada auxiliar ou regressora. O MRLS descreve a variável $Y$ como uma soma de uma quantidade determinística, e uma quantidade aleatória. A parte determinística, uma reta em função de $X$, representa a informação sobre $Y$ que já se pode "esperar", apenas com o conhecimento da variável $X$. A parte aleatória, denominada erro, representa os inúmeros fatores que, conjuntamente, podem interferir em $Y$. Assim, pode-se interpretar que o erro provoca uma distorção sobre a parte determinística de $Y$.

Segundo Subramanian et al (2007), utilizando-se $\beta_{0}$ e $\beta_{1}$ para denotar os coeficientes da reta; $\varepsilon$, a variável erro; $\sigma^{2}$, a variância da variável erro; $x_{i}$, um valor específico da variável $X$, e $y_{i}$, um valor específico da variável $Y$, pode-se sumarizar o MRLS como

$$
y_{i}=\beta_{0}+\beta_{1} \cdot x_{i}+\varepsilon_{i}
$$

Segundo Hoffman e Vieira (1998), ao estabelecer um modelo de regressão linear simples, pressupõe-se que:

- A relação entre $X$ e $Y$ é linear.

- Os valores de $X$ são fixos, isto é, $X$ não é uma variável aleatória.

- A média do erro é nula, isto é, $E\left[\varepsilon_{i}\right]=0$.

- Para um dado valor de $X$, a variância do erro é sempre $\operatorname{Var}\left[\varepsilon_{i}\right]=\sigma^{2}$, denominada variância residual. Dizemos então que o erro é homocedástico ou que temos homocedasticia (do erro ou da variável dependente).

- O erro de uma observação é não-correlacionado com o erro em outra observação, isto é, $E\left(\varepsilon_{i}, \varepsilon_{j}\right)=0$ para $i \neq j$.

- Os erros têm distribuição normal.

\subsubsection{O modelo de regressão linear múltipla (MRLM)}

Segundo Gujrati (2000), os conceitos de estimativa de intervalo e teste de hipótese, desenvolvidos anteriormente, estendem-se para os modelos com três ou mais variáveis. Embora sob muitos aspectos, esses conceitos possam ser aplicados diretamente ao modelo de regressão múltipla, 
algumas características adicionais são exclusivas de tais modelos, e são estas características que receberão maior atenção.

Pode-se afirmar que o MRLM é uma extensão do MRLS, Anderson et ali. (2002) e Hair et ali (2005) descrevem o MRLM da seguinte forma:

$$
y=\beta_{0}+\beta_{1} \cdot x_{1}+\beta_{2} \cdot x_{2}+\ldots+\beta_{p} \cdot x_{p}+\varepsilon .
$$

Onde $x_{1}, x_{2}, \ldots, x_{p}$ são constantes, $\beta_{0}, \beta_{1}, \beta_{2}, \ldots, \beta_{p}$ são parâmetros denominados coeficientes de regressão parciais, e $\varepsilon$ os resíduos.

Através da extensão do método dos mínimos quadrados empregado no MRLS, pode-se chegar à equação linear da regressão múltipla, isto é,

$$
\hat{y}=b_{0}+b_{1} \cdot x_{1}+b_{2} \cdot x_{2}+\ldots+b_{p} \cdot x_{p}
$$

\subsubsection{Medida corretiva na presença de correlação serial}

Na presença de correlação serial, os estimadores de Mínimos Quadrados Ordinários (MQO) são ineficientes sendo essencial procurar medidas corretivas. A solução depende do conhecimento sobre a natureza da interdependência das perturbações, uma das situações (e tratada neste estudo) é quando a estrutura da autocorrelação é desconhecida (WOOLDRIDGE, 2006; GUJARATI, 2000).

\section{Estrutura da autocorrelação desconhecida}

Embora simples de aplicar, a regressão de diferença generalizada é geralmente difícil de rodar, já que na prática, raramente se conhece $\rho$. Por isso, é preciso pensar em métodos alternativos, tal como o processo interativo de Cochrane-Orcutt.

\section{O processo interativo de Cochrane-Orcutt para estimar $\rho$.}

Uma alternativa para estimar $\rho$ a partir da estatística $d$ de Durbin Watson é o bastante usado método de Cochrane-Orcutt, que usa resíduos estimados $\hat{u}_{\mathrm{t}}$ para obter informações sobre o $\rho$ desconhecido.

Considere o modelo de duas variáveis:

$$
y_{t}=\beta_{0}+\beta_{1} \cdot x_{1}+\mu_{t}
$$

e suponha que $\hat{u}_{t}$ seja gerado pelo esquema AR(1), ou seja,

$$
\mu_{t}=\rho \mu_{t-1}+\varepsilon_{t}
$$

Cochrane e Orcutt recomendam então os seguintes passos para estimar $\rho$ :

1. Estime o modelo pela rotina usual dos MQO e obtenha os resíduos, $\hat{u}_{t}$.

2. Usando os resíduos estimados, rode a seguinte regressão: 


$$
\hat{\mu}_{t}=\hat{\rho} \hat{\mu}_{t-1}+v_{t}
$$

3. Usando o $\hat{\rho}$ obtido da equação (7), rode a equação de diferença generalizada:

$$
\left(Y_{t}-\hat{\rho} Y_{t-1}\right)=\beta_{1}(1-\hat{\rho})+\beta_{2} X_{t}-\hat{\rho} \beta_{2} X_{t-1}+\left(\mu_{t}-\hat{\rho} \mu_{t-1}\right)
$$

$$
Y_{t}^{*}=\beta_{t}^{*}+\beta_{2}^{*} X_{t}^{*}+\hat{e}_{t}
$$

4. A priori, não sabe se o $\hat{\rho}$ obtido da equação (7) é a "melhor" estimativa de $\rho$, substitua os valores de $\beta_{1}^{*}=\beta_{1}(1-\rho)$ e $\beta_{2}^{*}$ obtidos da equação (9) na regressão original (5) e obtenha os novos resíduos, digamos $\hat{\mu}_{t}^{* *}$, deste modo:

$\hat{\mu}_{t}^{* *}=Y_{t}-\hat{\beta}_{1}^{*}-\hat{\beta}_{2}^{*} X_{t}$

que pode ser calculado facilmente, pois $Y_{t}, X_{t}, \beta_{1}^{*}$ e $\beta_{2}^{*}$ são todos eles conhecidos.

5. Agora estime esta regressão: $\hat{\mu}_{t}^{* *}=\hat{\rho} \hat{\mu}_{t-1}^{* *}+w_{t}$

que é similar a equação (5). Assim, $\hat{\hat{\rho}}$ é a estimativa de segunda rodada de $\rho$. Como não sabemos se esta estimativa de segunda rodada de $\rho$ é a melhor estimativa de $\rho$, podemos entrar na estimativa de terceira rodada, e assim por diante. Como sugerem os passos anteriores, o método de Cochrane-Orcutt é iterativo (repetitivo). Mas até onde deve-se prosseguir? Em geral parar com as repetições sucessivas de $\rho$ quando este divergir para valores menores do que 0,01 (GUJARATI, 2000).

\section{Os resíduos}

A análise de um modelo de regressão tem uma relação muito forte com a qualidade do ajuste feito, bem como com a confiabilidade dos testes estatísticos sobre os parâmetros do modelo. Nesse sentido, a análise dos resíduos tem uma importância fundamental na verificação da qualidade dos ajustes de modelos. Basicamente, essa análise fornece evidências sobre possíveis violações nas suposições do modelo, tais como a de normalidade e a homocedasticidade, e quando for o caso ainda fornece indícios da falta de ajuste do modelo proposto (CHARNET, 1999; SUBRAMANIAN, 2007).

Pode-se avaliar a adequação do modelo de regressão ajustado plotando os resíduos no eixo vertical e os valores correspondentes aos valores de $X_{i}$ da variável independente no eixo horizontal. Se o modelo ajustado for apropriado para os dados, não haverá padrão aparente de resíduos em relação a $X_{i}$. No entanto, se o modelo ajustado não for apropriado, existirá uma relação entre os valores de $X_{i}$ e os resíduos $e_{i}$ (LEVINE, 2000). 
A melhor parametrização será aquela em que for calculado o menor percentual absoluto de erro médio (MAPE):

$$
M A P E=\frac{\sum\left|\frac{\left(x_{i}-y_{i}\right)}{x_{i}}\right|}{n} 100 \%
$$

onde $x_{i}$ são os valores observados e $y_{i}$ os valores estimados.

\section{Metodologia}

O conjunto de dados analisados trata-se de informações das variáveis de perfis de poços que medem propriedades das rochas atravessadas por esses poços, pertencentes a unidades geológicas da Bacia Sergipe-Alagoas de um campo de petróleo da Bacia Sedimentar Sergipe Alagoas. Alguns desses poços dispõem de um conjunto completo de perfis, inclusive o sônico. Serão identificadas as possíveis estratificações das amostras como: profundidade, tipos litológicos (composicionais), etc...

\section{Caracterização das variáveis de perfis:}

- Caliper (CALI): Perfil que fornece o diâmetro medido ponto a ponto em toda a extensão de um poço. É um indicativo importante da qualidade da leitura dos perfis. Alguns perfis tem seu limite operacional limitados a determinados diâmetros de poços, como o perfil sônico que tem seu limite em 12 1/4 de polegada. Os diferentes perfis de poços são afetados de forma diferenciada pelas variações observadas no Caliper. Os perfis que correm centralizados no poço são de forma geral os mais afetados (ILD, DT) pelas variações no diâmetro dos poços ao passo que os que correm com sapatas de contato nas paredes do poço são menos afetados. Essa variável é medida em polegadas.

- Diâmetro da Broca (DB): variável que define o diâmetro nominal da broca que perfurou determinado intervalo de poço, sendo que um poço geralmente tem diferentes intervalos perfurados com brocas de diferentes diâmetros. $\mathrm{O} D B$ é medido em polegadas.

- Arrombamento de Poço (Dcali): é uma variável calculada (CALI - DB), mede o quanto o diâmetro do poço se afasta do diâmetro nominal da broca que perfurou determinado trecho, esse valor é chamado de "arrombamento do poço". Quando essa variável tem alta freqüência provoca "rugosidades" nas paredes dos poços sendo que essas irregularidades afetam a qualidade das leituras dos perfis, principalmente os perfis que correm com sapatas de contato junto as paredes dos poços como o perfil de Nêutrons e o Densidade. Essa variável é medida em polegadas

- Profundidade (Prof): é a profundidade do ponto de leitura dentro do poço. Sua escala de medida é em metros. Seu referencial de medida, isto é, o zero, é a Mesa Rotativa (MR) da sonda de 
perfuração, que em geral é um número menor que 10 metros. Para ser corrigida ao Nível Topográfico basta subtrair a MR. A profundidade é uma variável que para ser usada adequadamente requer o conhecimento da geologia da área, isto é: estar familiarizado com os diferentes Níveis Estratigráficos. A sua correlação com outras variáveis de perfis requer uma interpretação geológica. De forma geral a velocidade sônica das rochas (1/DT) e a densidade (RHOB) crescem com a profundidade em função do soterramento e conseqüente compactação das rochas.

- Raios Gama (GR): É a medida da radioatividade total presente nas rochas. Este perfil é utilizado, principalmente, para separar tipos diferentes de rochas, já que as argilas apresentam elevados teores de elementos radioativos e os arenitos e carbonatos têm baixa radioatividade. Uma outra aplicação é na correlação entre poços para rastrear lateralmente os Níveis Estratigráficos. Esse perfil, apesar de correr centralizado é pouco afetado pelo arrombamento do poço. Sua unidade de medida é em graus API.

- Indução (ILD): Curva de resistividade do perfil Eletro-indução. Mede a resistividade das rochas. É aplicado para cálculo de saturação e identificação dos fluidos e correlação entre os poços. Essa variável é afetada principalmente pela variação dos fluidos presentes nos poros da rocha, portanto deve ser usada com bastante critério, sempre identificando o fluido presente nas rochas reservatório. É medido em ohm.metro.

- Densidade (RHOB): Mede a densidade das rochas. É o principal perfil para a estimativa da porosidade Normalmente é medida em $\mathrm{g} / \mathrm{cm}^{3}$ (grama por centímetro cúbico).

- Sônico (DT): Mede o tempo necessário para uma onda sonora percorrer um pé de rocha, esse tempo é chamado de tempo de trânsito. Esse tempo é inversamente proporcional a velocidade sônica da rocha. É utilizado para a estimativa da porosidade, correlação de poços, estimativas do grau de compactação das rochas, estimativas das constantes elásticas da rocha, detecção de fraturas e apoio à sísmica (sismograma sintético). É medido em microsegundos por pé.

\section{Caracterização das variáveis geológicas:}

- Níveis Estratigráficos (N_Est): Esta variável indica os diferentes níveis geológicos atravessados pelos poços. Podem diferir uns dos outros em função de diferentes atributos como idades geológicas das rochas, origens em diferentes ambientes sedimentares que em última análise vão se traduzir em rochas com diferentes composições mineralógicas ocasionando variações dos aspectos físicos e químicos destas rochas. O mais importante é que esses Níveis Estratigráficos podem ser rastreados lateralmente, poço a poço com base em suas assinaturas dos perfis. 


\section{Resultados e discussões}

Foram utilizados os valores das variáveis básicas que compõem o perfil sônico (DT/ILD/RHOB/GR/Dcali) de poços de explotação para compor este estudo. Alguns desses poços dispõem de um conjunto completo de perfis, inclusive o sônico (DT). Foram utilizados todos os valores de cada poço, excluído apenas regiões que não possui todas as variáveis.

\subsection{Análise dos poços}

\subsection{Análise descritiva das variáveis}

A Tabela 1 mostra os níveis estratigráficos contidos nos poços de petróleo pertencentes a Bacia Sedimentar Sergipe Alagoas. A Tabela 1 mostra o início e o final de cada poço (em metros), assim como o topo e a base de cada nível estratigráfico. A Tabela 1 mostra que só o poço P2 possui todos os níveis estratigráficos. $\mathrm{O}$ poços $\mathrm{P} 1$ não possui o nível estratigráfico $2 \mathrm{M}$ e $6 \mathrm{~B} \mathrm{O}$ poço $\mathrm{P} 3$ apesar de não possuir todos os níveis (2M, $5 \mathrm{~S}$ e $6 \mathrm{~B})$, é o poço com maior profundidade. O poço $\mathrm{P} 4$ não possui o nível $6 \mathrm{~B}$ e o poço $\mathrm{P} 5$ não possui os níveis $5 \mathrm{~S}$ e $6 \mathrm{~B}$.

Tabela 1 - Níveis Estratigráficos dos poços

\begin{tabular}{|c|c|c|c|c|c|c|c|c|c|c|}
\hline \multirow[b]{2}{*}{ Níveis } & \multicolumn{2}{|c|}{ POÇO P1 } & \multicolumn{2}{|c|}{ POÇO P2 } & \multicolumn{2}{|c|}{ POÇO P3 } & \multicolumn{2}{|c|}{ POÇO P4 } & \multicolumn{2}{|c|}{ POÇO P5 } \\
\hline & $\begin{array}{c}\text { Topo } \\
\text { (em } \\
\mathrm{m})\end{array}$ & $\begin{array}{c}\text { Base } \\
(\mathrm{em} \mathrm{m})\end{array}$ & $\begin{array}{c}\text { Topo } \\
\text { (em m) }\end{array}$ & $\begin{array}{c}\text { Base } \\
(\mathrm{em} \mathrm{m})\end{array}$ & $\begin{array}{c}\text { Topo } \\
\text { (em } \\
\mathrm{m})\end{array}$ & $\begin{array}{c}\text { Base } \\
(\mathrm{em} \mathrm{m})\end{array}$ & $\begin{array}{c}\text { Topo } \\
\text { (em } \\
\mathrm{m})\end{array}$ & $\begin{array}{c}\text { Base } \\
(\mathrm{em} \mathrm{m})\end{array}$ & $\begin{array}{c}\text { Topo } \\
\text { (em } \\
\mathrm{m})\end{array}$ & $\begin{array}{c}\text { Base } \\
(\mathrm{em} \mathrm{m})\end{array}$ \\
\hline $1 \mathrm{C}$ & 121 & 588,875 & 115 & 584,75 & 103 & 784,75 & 124 & 724,75 & 147 & 397,75 \\
\hline $2 \mathrm{M}$ & - & - & 585 & 617,75 & - & - & 725 & 770,75 & 398 & 517,75 \\
\hline $3 \mathrm{P}$ & 589 & 1143,875 & 618 & 1026,75 & 785 & 1275,75 & 771 & 1291,75 & 518 & 1015,75 \\
\hline $4 \mathrm{~B}$ & 1144 & 2735,875 & 1027 & 2545,75 & 1276 & 2842,75 & 1292 & 2734,75 & 1016 & 2146,75 \\
\hline $5 \mathrm{~S}$ & 2736 & 2769 & 2546 & 2634,75 & - & - & 2735 & 2797,75 & - & - \\
\hline $6 \mathrm{~B}$ & - & - & 2635 & 2663,75 & - & - & - & - & - & - \\
\hline
\end{tabular}

Fonte: Autoria própria (2009)

Para compreender melhor os dados foram construídos os gráficos representativos do perfil sônico (DT) adquirido pelos poços P1, P2, P3, P4 e P5, conforme Figura 2.

Nota-se, na Figura 2, que os poços possuem características semelhantes, ambos possuem uma tendência de decrescimento nos valores encontrados de DT em direção a base do poço, a quantidade maior variabilidade encontra-se no nível $1 \mathrm{C}$ e $4 \mathrm{~B}$. 
Nota-se, através da Figura 2, que em todos os poços a tendência de decrescimento segue desde o nível estratigráfico $1 \mathrm{C}$ até a base dos poços. A Figura 2, também mostra as mudanças nos gradientes em função dos níveis estratigráficos, assim como os deslocamentos das médias, também em função dos níveis.

Os registros das estatísticas, pelo método dos momentos dos poços, estão apresentados na Tabelas 2. A profundidade central (meio) do poço P1 é 1446,4m, do poço P2 é 1686,5m, do poço P3 é 1445,88m, do poço P4 é 2103,50m e do poço P5 é 1593,13m. Os registros das estatísticas servirão para detectar a homogeneidade das variáveis. 
Figura 2 - Gráfico da variável DT versus profundidade dos poços

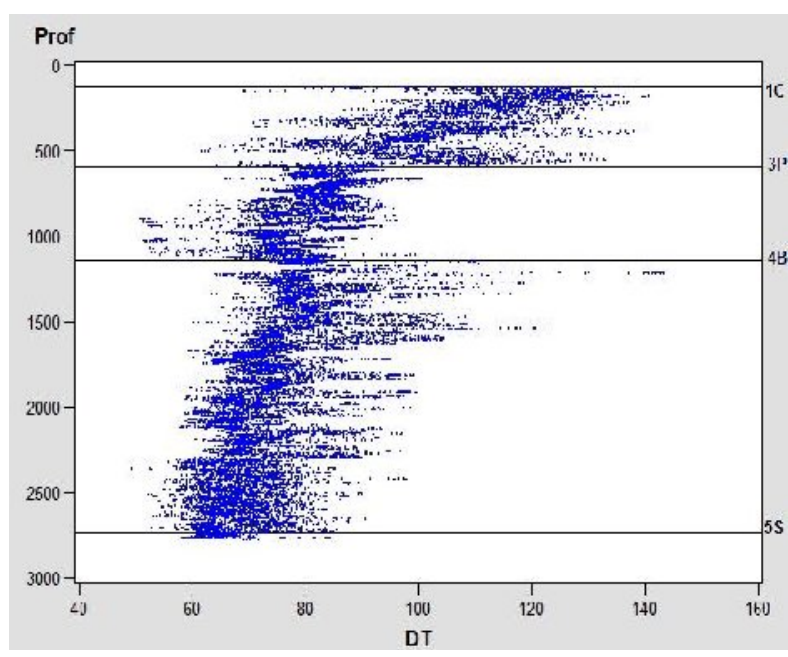

(a) P1

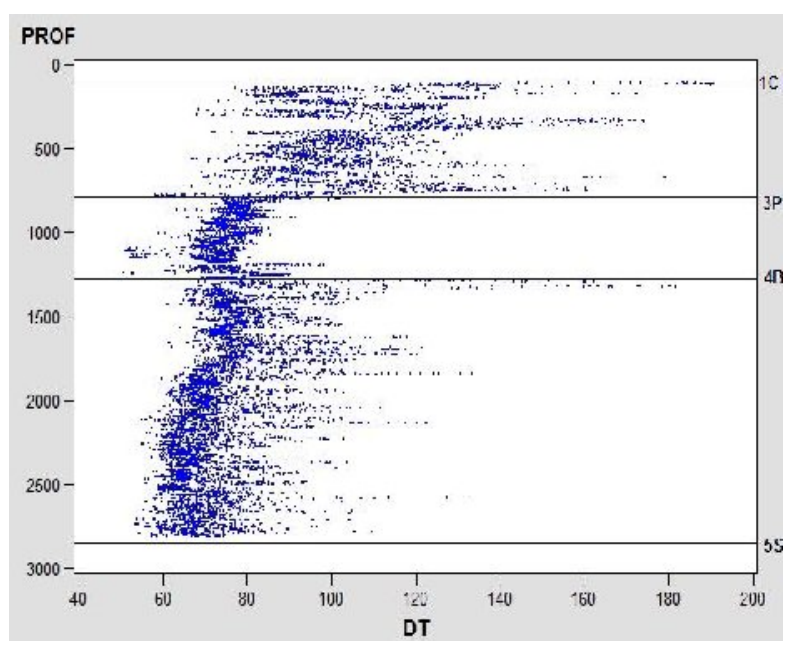

(c) P3

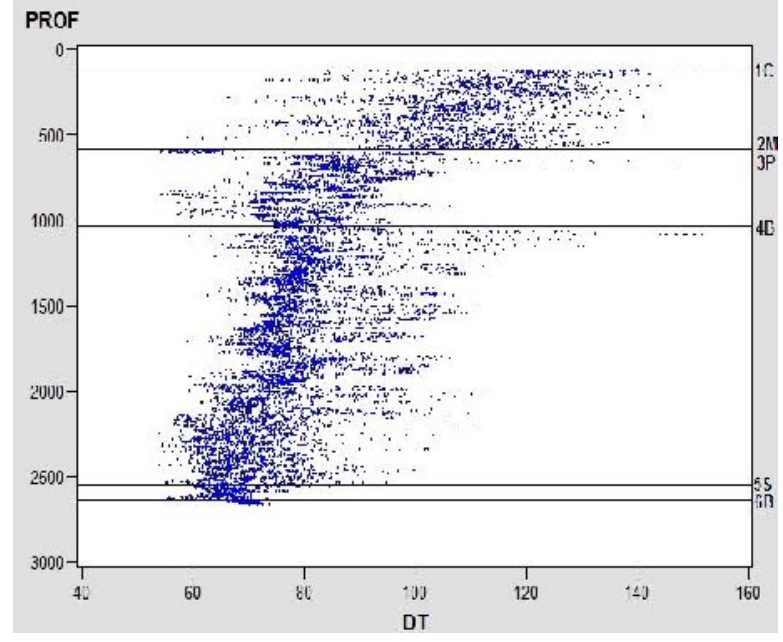

(b) P2

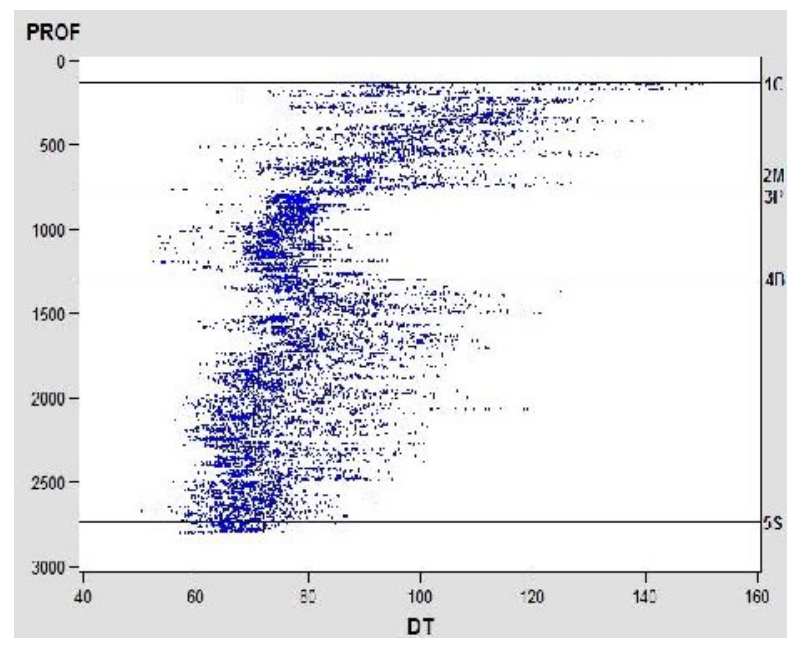

(d) P4

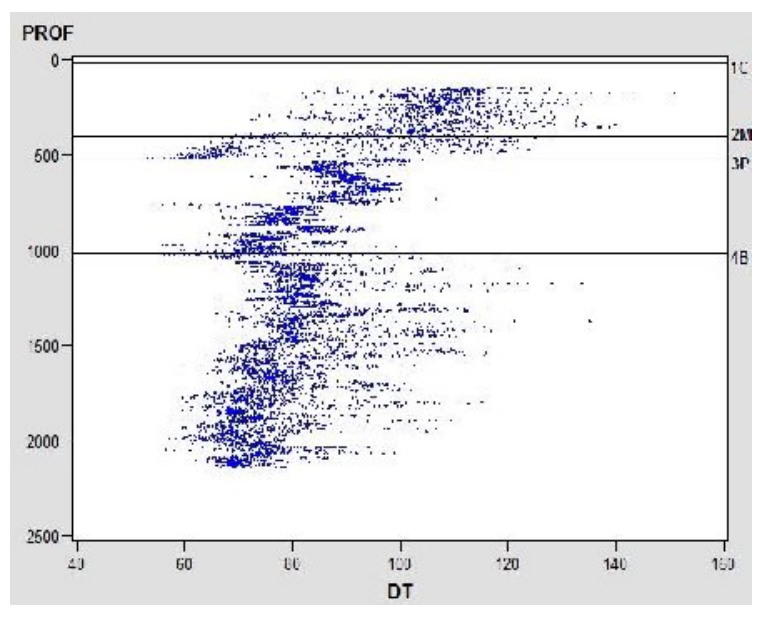

(e) P5 
Tabela 2 - Resumo das estatísticas descritivas dos poços

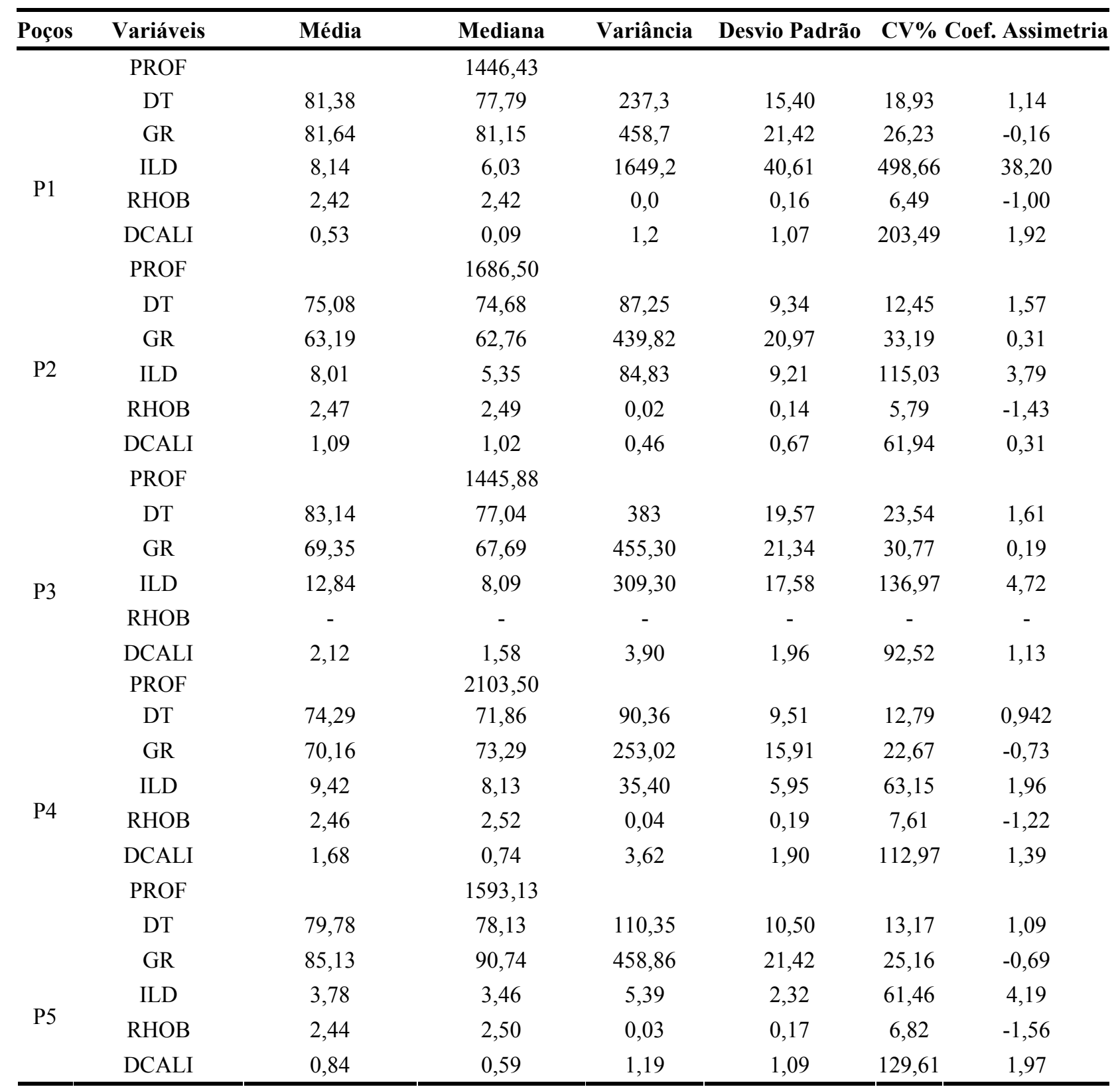

Fonte: Autoria própria (2009)

O Poço P3 não possui valores para a variável RHOB. A variável RHOB (com Coeficiente de Variação de $6,49 \%$ para o poço $\mathrm{P} 1,5,79 \%$ para o poço $\mathrm{P} 2$ e $6,82 \%$ para o poço $\mathrm{P} 5$ ) se destaca como a variável mais homogênea. Enquanto a variável ILD com Coeficiente de Variação de 498,65(poço P1), 115,03(poço P2), 136,97 (poço P3), 63,15\% (poço P4) e 61,46\% (poço P5) se destaca como a mais heterogênea, sendo recomendado fazer uma transformação logarítmica na variável ILD.

Observa-se, pela Tabela 2, que as variáveis DT, ILD, Dcali, apresentam uma assimetria positiva indicando que a distribuição apresenta uma cauda para o lado direito. Porém, a variável RHOB apresenta uma assimetria negativa, apresentando uma cauda para o lado esquerdo. O que 
difere de um poço para outro é a variável GR, que é uma variável assimétrica positiva no poço P2 e P3.

\subsection{Análise do modelo encontrado para cada poço}

Os coeficientes do modelo de regressão múltipla pelo método de mínimos quadrados (MQO) do perfil sônico sintético para os poços dão origem as equações:

Poço P1:

$$
\begin{gathered}
D T=106,38-0,6379 \text { Prof }+0,4116 \text { GR }-0,2259 L N \text { ILD }-0,0999 R H O B+0,1998 \text { D cali } \\
\mathrm{R}=0,85 \quad \mathrm{R}^{2}=73,09 \% \quad \mathrm{R}^{2} \text { Adjust }=73,08 \% \quad \text { Std da Estimativa }=7,9919 \quad \text { DW }=0,068 \quad \text { MAPE }=7,66 \%
\end{gathered}
$$

Poço P2:

$$
\begin{aligned}
& D T=123,39-0,3667 \text { Prof }+0,2918 G R-0,4105 L N \text { ILD -0,2558RHOB + 0,1265Dcali }
\end{aligned}
$$

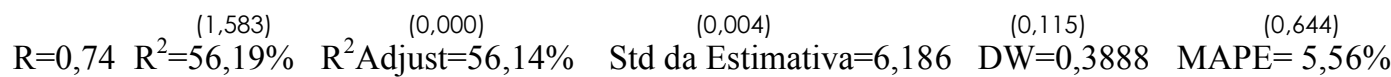

Poço P3:

$$
D T=\underset{(0,579)}{85,88}-\underset{(0,00)}{0,688} \operatorname{Pr} \text { of }+\underset{(0,006)}{0,3088 G R}-\underset{(0,124)}{0,143 \text { LnILD }}+\underset{(0,068)}{0,427} \text { DCali }
$$

$\mathrm{R}=0,81 \quad \mathrm{R}^{2}=66,51 \% \quad \mathrm{R}^{2}$ Adjust $=66,49 \% \quad$ Std da Estimativa=11,27 $\quad \mathrm{DW}=0,1893 \quad$ MAPE=9,35\%

Poço P4:

$$
\begin{gathered}
D T=128,36-0,1423 \text { Prof }-0,2513 G R-0,1150 L N \text { ILD }-0,2317 R H O B+0,4718 \text { D cali } \\
\begin{array}{ccccc}
(2,787) & (0,000) & (0,009) & (0,249) & (1,091) \\
\mathrm{R}=0,75 & \mathrm{R}^{2}=56,62 \% & \mathrm{R}^{2} \text { Adjust }=56,54 \% & \text { Std da Estimativa }=6,2664 & \mathrm{DW}=0,4221 \mathrm{MAPE}=6,19 \%
\end{array}
\end{gathered}
$$

Poço P5:

$$
\begin{aligned}
& D T=111,58-0,1803 \text { Prof }+0,4541 G R-0,3608 L N \text { ILD -0,2552RHOB + 0,2975Dcali }
\end{aligned}
$$

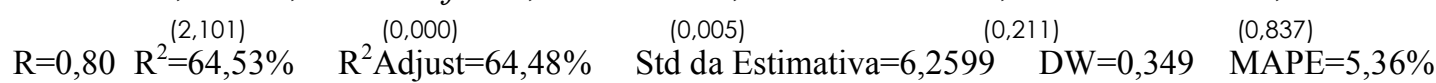

A estatística de Durbin-Watson (DW) avalia a existência de independência dos resíduos, ou seja, testa a hipótese nula de que a covariância entre as variáveis residuais seja zero. Considerando as observações para os poços, e as cinco variáveis explicativas, o valor da estatística Durbin-Watson para todos os poços, é substancialmente menor do que o valor de referência 2 (dois), o que indica que a correlação entre os resíduos estão presentes.

Deve ter maior atenção na correlação serial quando os dados se referem a observações espaciais, assim foi necessário aplicar o método dos Mínimos Quadrados Generalizados (MQG), utilizando-se a estimação de Cochrane-Orcutt (CO) para remover a auto-correlação dos resíduos. 
Foi feito a estimação nas equações $11,12,13,14$ e 15 e a título de comparação apresenta-se os resultados na Tabela 3. A quantidade de observações usadas $(\mathrm{N})$ não corresponde a profundidade do poço, por serem coletadas valores de distâncias diferentes de um poço para outro.

Tabela 3 - Comparação entre modelos dos poços

\begin{tabular}{cccccccccccc}
\hline & \multicolumn{2}{c}{ POÇO P1 } & \multicolumn{2}{c}{ POÇO P2 } & \multicolumn{2}{c}{ POÇO P3 } & \multicolumn{2}{c}{ POÇO P4 } & \multicolumn{2}{c}{ POÇO P5 } \\
\hline Coef. & MQO & CO & MQO & CO & MQO & CO & MQO & CO & MQO & CO \\
& 106,38 & 0,5835 & 123,39 & 18,99 & 85,888 & 5,158 & 128,36 & 20,61 & 111,58 & 43,738 \\
Intercepto & $(-0,974)$ & $(-0,018)$ & $(-1,583)$ & $(-0,309)$ & $(-0,579)$ & $(-0,101)$ & $(-2,787)$ & $(-0,955)$ & $(-2,101)$ & $(-0,265)$ \\
& $-0,6372$ & $-0,0496$ & $-0,3667$ & $-0,1138$ & $-0,688$ & $-0,135$ & $-0,1423$ & $-0,0574$ & $-0,1803$ & $-0,0629$ \\
Prof & $(0)$ & $(-0,001)$ & $(0)$ & $(0)$ & $(0)$ & $(-0,001)$ & $(0)$ & $(-0,002)$ & $(0)$ & $(-0,002)$ \\
& 0,4116 & 0,1713 & 0,2918 & 0,1586 & 0,3088 & 0,154 & $-0,2513$ & $-0,032$ & 0,4541 & 0,264 \\
GR & $(-0,003)$ & $(-0,004)$ & $(-0,004)$ & $(-0,007)$ & $(-0,006)$ & $(-0,009)$ & $(-0,009)$ & $(-0,014)$ & $(-0,005)$ & $(-0,009)$ \\
& $-0,2259$ & 0,0301 & $-0,4105$ & $-0,2607$ & $-0,143$ & $-0,108$ & $-0,115$ & $-0,1018$ & $-0,3608$ & $-0,1325$ \\
Ln(ILD) & $(-0,081)$ & $(-0,148)$ & $(-0,115)$ & $(-0,268)$ & $(-0,124)$ & $(-0,341)$ & $(-0,249)$ & $(-0,571)$ & $(-0,211)$ & $(-0,784)$ \\
& 0,1998 & 0,0002 & 0,1265 & 0,021 & 0,427 & 0,171 & 0,4718 & 0,3166 & 0,2975 & 0,1636 \\
Dcali & $(-0,067)$ & $(-0,7)$ & $(-0,139)$ & $(-0,229)$ & $(-0,068)$ & $(-0,066)$ & $(-0,113)$ & $(-0,115)$ & $(-0,113)$ & $(-0,113)$ \\
& $-0,0999$ & $-0,0354$ & $-0,2558$ & $-0,2956$ & - & - & $-0,2317$ & $-0,1654$ & $-0,2552$ & 0,0669 \\
RHOB & $(-0,426)$ & $(-0,308)$ & $(-0,644)$ & $(-0,666)$ & - & - & $(-1,091)$ & $(-1,225)$ & $(-0,837)$ & $(-1,032)$ \\
P & - & 0,028 & - & 0,023 & - & 0,004 & - & 0,023 & - & 0,022 \\
N & 21162 & 21158 & 4827 & 4823 & 10730 & 10724 & 2594 & 2590 & 4314 & 4308 \\
DW & 0,068 & 1,94 & 0,3888 & 1,98 & 0,18 & 1,99 & 0,4221 & 1,952 & 0,349 & 1,96 \\
R ${ }^{2}$ & 0,73 & 0,034 & 0,56 & 0,24 & 0,66 & 0,09 & 0,56 & 0,23 & 0,64 & 0,11 \\
& & & & Variável Dependente: DT & & & & \\
\hline
\end{tabular}

Fonte: Autoria Própria (2009)

O método Cochrane-Orcutt registra observações a menos que o MQO, pois foi utilizado quatro iterações para os poços P1,P2 e P4; e seis iterações para os poços P3 e P5.

Um $\mathrm{R}^{2}$ é informado na estimação Cochrane-Orcutt, que é bem menor que o $\mathrm{R}^{2}$ da estimação MQO, porém esses $\mathrm{R}^{2}$ não devem ser usados para comparação, pois no MQO o $\mathrm{R}^{2}$ é baseado na regressão com as variáveis dependentes e independentes sem transformação.

No método Cochrane-Orcutt, o $\mathrm{R}^{2}$ provém da regressão final da variável dependente transformada sobre as variáveis transformadas. Com as informações da Tabela 4 observa-se a partir do Teste $t$ de student e, dos respectivos p-valores, para os poços $\mathrm{P} 1$ e P2, que nem todos os coeficientes são significativos, ou seja, a variável Dcali não possui influência na variável DT, devendo ser excluída do modelo.

A análise foi refeita para os poços P1, P2 e P4 retirando-se a variável DCali do modelo dos poços e P1 e P2 e, a variável GR do poço P4. Um novo modelo foi encontrado, cujos resultados encontram-se na Tabela 5, onde observa-se a partir do Teste $t$ de student $\mathrm{e}$, dos novos respectivos pvalores que todos os coeficientes são significativos 
Tabela 4 - Coeficientes dos modelos encontrados

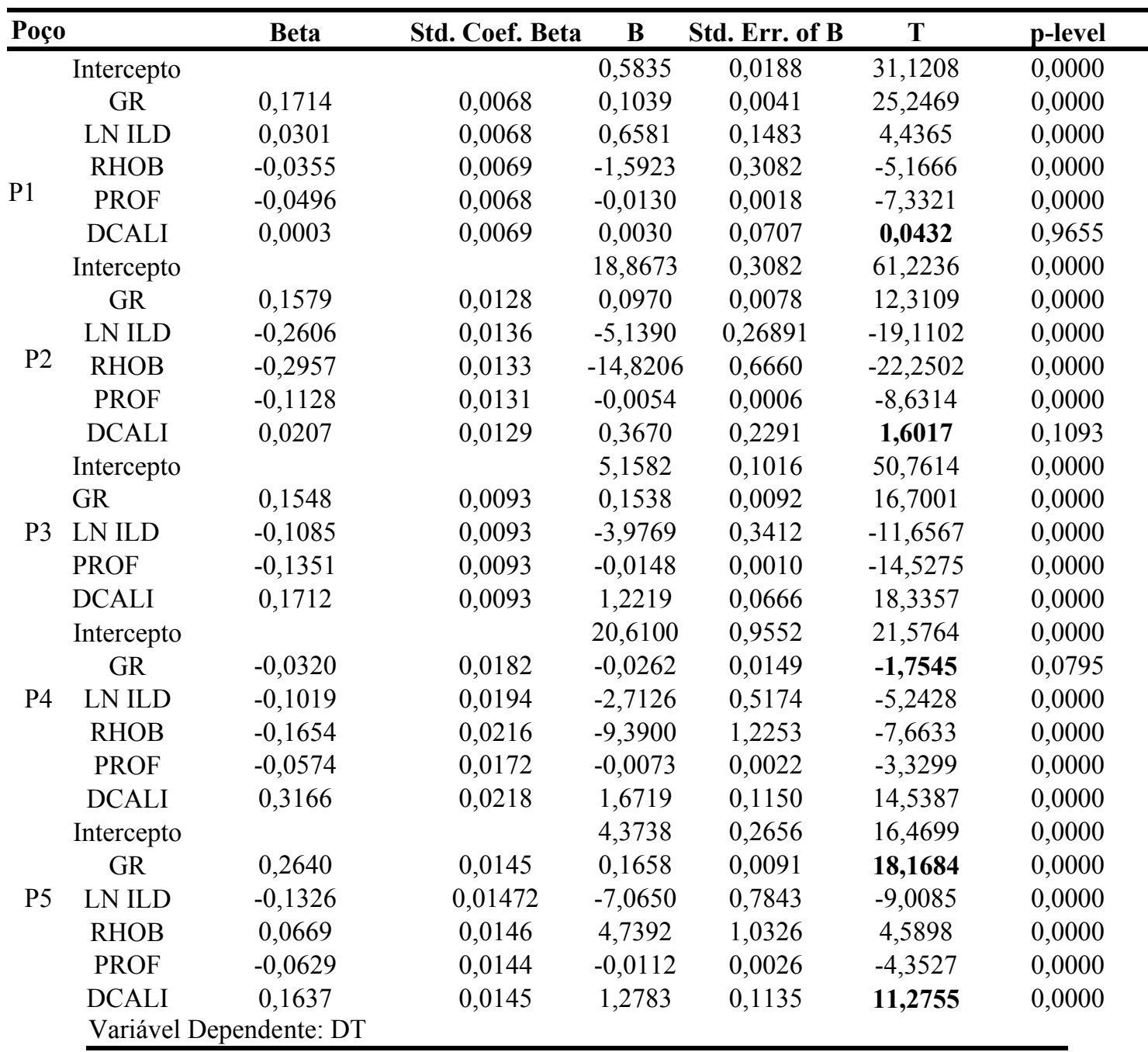

Fonte: Autoria Própria (2009)

Tabela 5-Coeficientes do modelo para o poço P1

\begin{tabular}{|c|c|c|c|c|c|c|c|}
\hline Poço & & Beta & Std. Coef. Beta & B & Std. Err. of B & $\mathbf{t}$ & p-level \\
\hline \multirow{6}{*}{ P1 } & Intercepto & & & 0,5836 & 0,0187 & 31,1688 & 0,0000 \\
\hline & GR & 0,1713 & 0,0068 & 0,1039 & 0,0041 & 25,3057 & 0,0000 \\
\hline & LN ILD & 0,0301 & 0,0068 & 0,6577 & 0,1480 & 4,4434 & 0,0000 \\
\hline & RHOB & $-0,0355$ & 0,0068 & $-1,5947$ & 0,3032 & $-5,2592$ & 0,0000 \\
\hline & PROF & $-0,0495$ & 0,0068 & $-0,0130$ & 0,0018 & $-7,3327$ & 0,0000 \\
\hline & Intercepto & & & 18,9559 & 0,3032 & 62,5171 & 0,0000 \\
\hline \multirow{4}{*}{$\mathrm{P} 2$} & GR & 0,1609 & 0,0127 & 0,0989 & 0,0079 & 12,6924 & 0,0000 \\
\hline & LN ILD & $-0,2996$ & 0,0131 & $-15,0170$ & 0,6548 & $-22,9328$ & 0,0000 \\
\hline & RHOB & $-0,2602$ & 0,0136 & $-5,1315$ & 0,2689 & $-19,0817$ & 0,0000 \\
\hline & PROF & $-0,1106$ & 0,0130 & $-0,0053$ & 0,0006 & $-8,5099$ & 0,0000 \\
\hline \multirow{5}{*}{ P4 } & Intercepto & & & 20,4936 & 0,9533 & 21,4978 & 0,0000 \\
\hline & LN ILD & $-0,0943$ & 0,0189 & $-2,5121$ & 0,5048 & $-4,9762$ & 0,0000 \\
\hline & RHOB & $-0,1752$ & 0,0209 & $-9,9445$ & 1,1844 & $-8,3965$ & 0,0000 \\
\hline & PROF & $-0,0581$ & 0,0172 & $-0,0074$ & 0,0022 & $-3,3662$ & 0,0008 \\
\hline & DCALI & 0,3104 & 0,0215 & 1,6393 & 0,1135 & 14,4395 & 0,0000 \\
\hline
\end{tabular}

Fonte:Autoria Própria (2009) 
A Tabela 6 mostra a análise de variância do modelo encontrado

Tabela 6 - ANOVA da regressão

\begin{tabular}{|c|c|c|c|c|c|c|}
\hline Poço & & Soma dos Quadrados & GL & Média Quadrática & $\mathbf{F}$ & Sig \\
\hline \multirow{4}{*}{ P1 } & Regressão & 1138,26 & 4 & 284,5644 & 191,58 & 0,0000 \\
\hline & Resíduo & 31418,88 & 21153 & 1,4854 & & \\
\hline & Total & 32557,14 & & & & \\
\hline & Regressão & 20443,11 & 4 & 510,778 & 398,81 & 0,0000 \\
\hline \multirow{2}{*}{$\mathrm{P} 2$} & Resíduo & 617142,80 & 4818 & 12,810 & & \\
\hline & Total & 82185,92 & & & & \\
\hline \multirow{3}{*}{ P3 } & Regressão & 2733158 & 4 & 683289,4 & 5325,390 & 0,0000 \\
\hline & Resíduo & 1376102 & 10725 & 128,3 & & \\
\hline & Total & 4109260 & & & & \\
\hline \multirow{3}{*}{ P4 } & Regressão & 10904,46 & 4 & 2726,114 & 197,5610 & 0,0000 \\
\hline & Resíduo & 35670,03 & 2585 & 13,799 & & \\
\hline & Total & 46574,49 & & & & \\
\hline \multirow{3}{*}{ P5 } & Regressão & 4650,69 & 5 & 930,1384 & 112,1491 & 0,0000 \\
\hline & Resíduo & 35679,78 & 4302 & 8,2938 & & \\
\hline & Total & 40330,47 & & & & \\
\hline \multicolumn{7}{|c|}{$\begin{array}{l}\text { a.Preditores: (Constant), PROF, GR, Dcali e Ln (ILD) } \\
\text { b.Variável Dependente: DT }\end{array}$} \\
\hline
\end{tabular}

Fonte: Autoria Própria (2009)

A análise da variância contida na Tabela 6 fornece o valor do teste $\mathrm{F}$ para se verificar a hipótese de nulidade de que todos os coeficientes sejam estatisticamente iguais a zero, contra a hipótese alternativa de que pelo menos um desses coeficientes seja diferente de zero.

Dado o valor do teste $\mathrm{F}$, e confirmado pela estatística do p-valor, 0,000 , confirma-se que pelo menos um coeficiente é estatisticamente diferente de zero. Como o F calculado para todos os poços são superiores ao valor do $\mathrm{F}$ crítico $(2,45)$, pode-se concluir que a regressão é significativa. Os coeficientes de regressão do modelo do perfil sônico sintético para os poços dão origem as equações:

Poço P1

$$
\begin{aligned}
& D T=0,5835-0,0496 \text { Prof }+0,1713 G R-0,0301 L N \text { ILD -0,0355RHOB } \\
& \begin{array}{llll}
(0,018) \quad(0,001) \quad(0,004) \quad(0,148) \quad(0,303)
\end{array} \\
& \mathrm{R}=0,18 \quad \mathrm{R}^{2}=3,49 \% \quad \mathrm{R}^{2} \text { Adjust }=3,47 \% \quad \text { Std da Estimativa }=1,2188 \quad \mathrm{DW}=1,94 \quad \text { MAPE }=1,36 \% \\
& \text { Poço P2 } \\
& D T=18,95-0,1106 \text { Prof }+0,1609 G R-0,2996 L N \text { ILD -0,2601RHOB } \\
& \begin{array}{llll}
(0,303) & (0,000) & (0,007) & (0,654)
\end{array} \\
& \mathrm{R}=0,49 \quad \mathrm{R}^{2}=24,98 \% \quad \mathrm{R}^{2} \text { Adjust }=24,90 \% \quad \text { Std da Estimativa }=3,5791 \quad \mathrm{DW}=1,98 \quad \text { MAPE }=2,24 \% \text {, } \\
& \text { Poço P3 } \\
& D T=5,158-0,135 \text { Prof }+0,154 G R-0,1084 L N I L D+0,171 D C a l i \\
& \begin{array}{lllll}
(0,101) & (0,001) \quad(0,009) \quad(0,341) & (0,066)
\end{array} \\
& \mathrm{R}=0,30 \quad \mathrm{R}^{2}=9,14 \% \quad \mathrm{R}^{2} \text { Adjust }=9,11 \% \quad \text { Std da Estimativa }=4,20 \quad \mathrm{DW}=1,99 \quad \text { MAPE }=2,07 \% \\
& \text { Poço P4 } \\
& D T=20,49-0,0580 \text { Prof - 0,0943LN ILD -0,1752RHOB + 0,3104DCali } \\
& \begin{array}{lllll}
(0,953) & . .(0,002) \quad(0,504) \quad(1,184) & (0,113)
\end{array}
\end{aligned}
$$




\section{Poço P5}

$D T=4,3738+0,2640 G R-0,1325 L N I L D+0,0669 R H O B-0,0629$ Prof $+0,1636$ Dcal $(0,265) \quad(0,009)$

$(0,784)$

$(0,113)$

$\mathrm{R}=0,33 \quad \mathrm{R}^{2}=11,53 \% \quad \mathrm{R}^{2}$ Adjust $=11,42 \% \quad$ Std da Estimativa=2,879 $\quad \mathrm{DW}=1,96 \quad \mathrm{MAPE}=2,17 \%$

Figura 3 - Gráficos dos resíduos versus profundidade dos poços

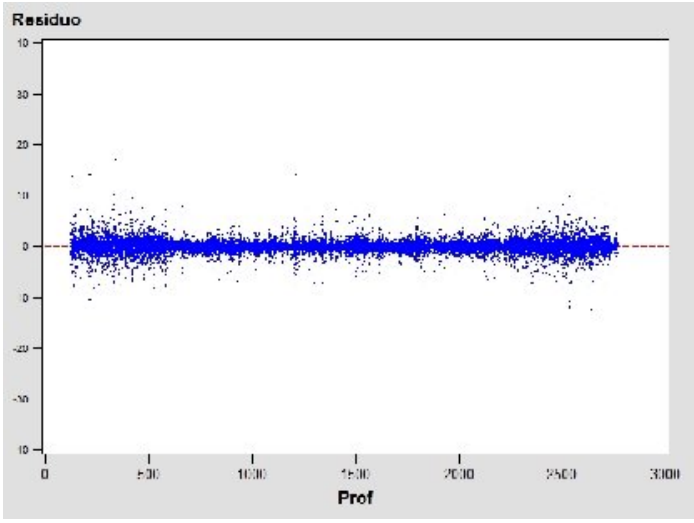

(a) P1

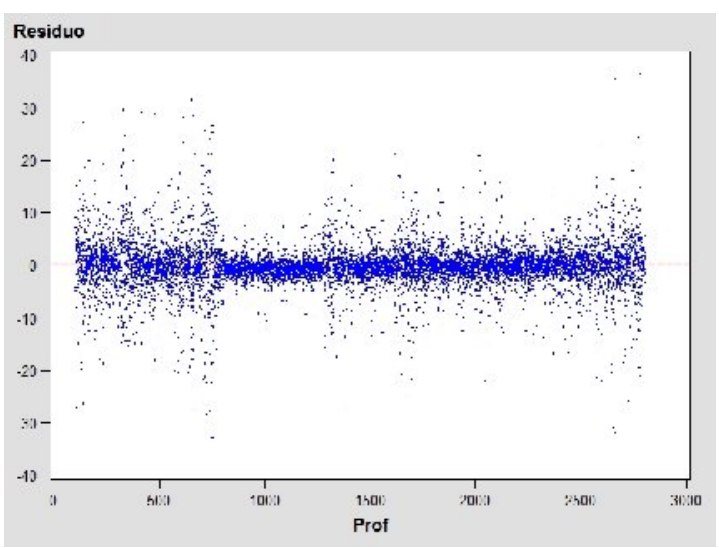

(c) P3

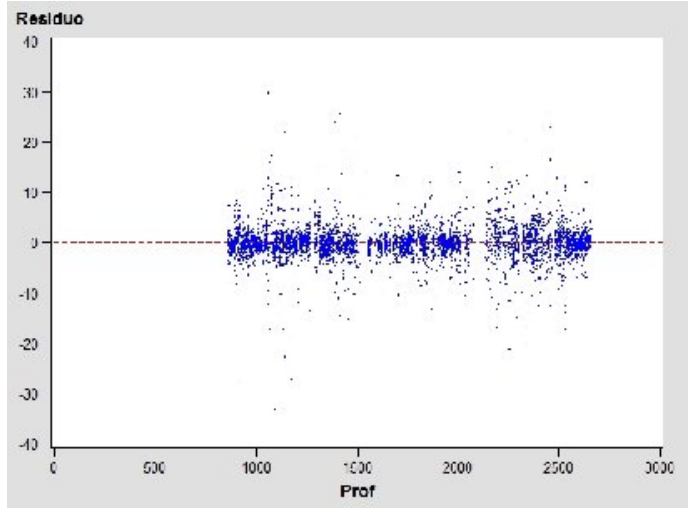

(b) P2

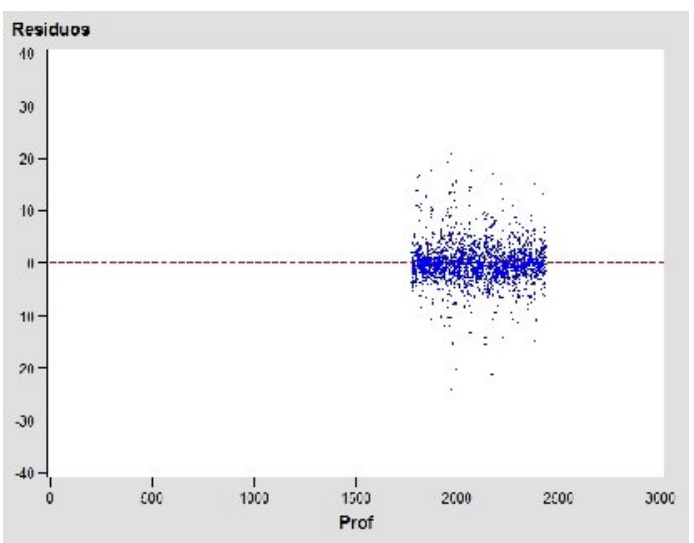

(d) P4

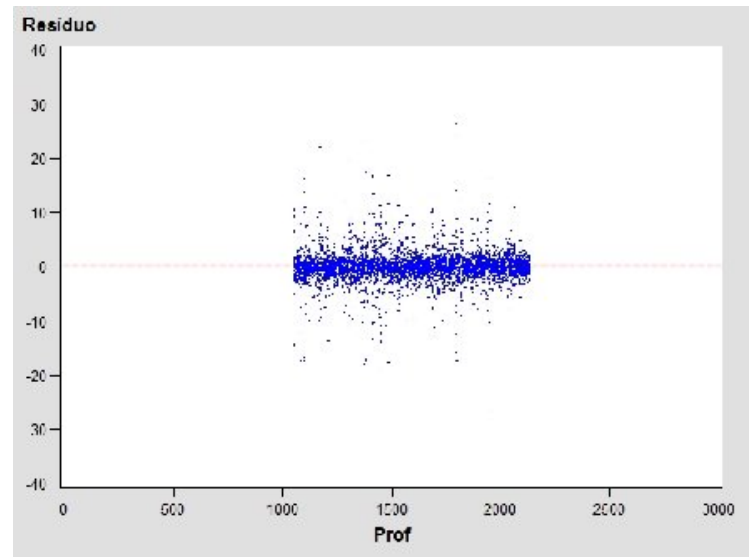

(e) P5 
A estatística de Durbin-Watson do modelo proposto para as variáveis explicativas estão próximas do ponto de referência $(2,00)$, o que indica que a correlação entre os resíduos não estão mais presente.

O critério de validação utilizado foi o Erro Médio Absoluto Percentual (MAPE). Todos os modelos obtiveram um MAPE menor do que 2,65\%, que consiste em um bom ajuste. Com as equações encontradas estimou-se os valores dos resíduos para os poços P1, P2, P3, P4 e P5, que se pode observar através dos gráficos representativos na Figura 3[(a), (b), (c), (d) e (e)].

Figura 4 - Gráficos dos resíduos versus DT dos poços

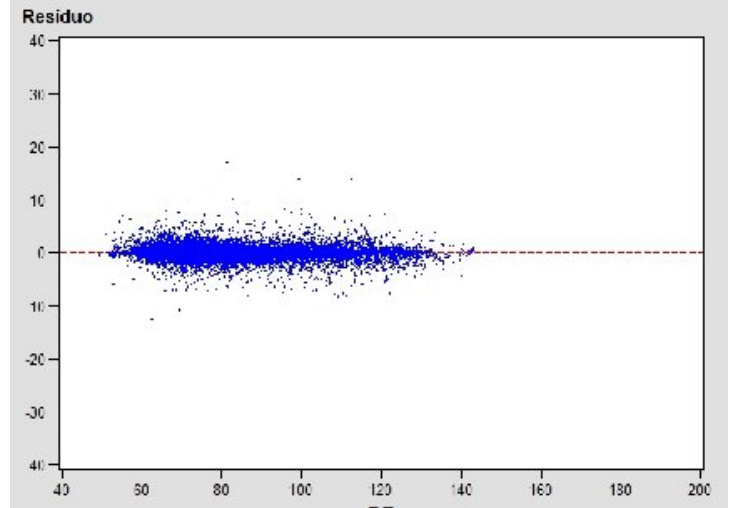

(a) P1

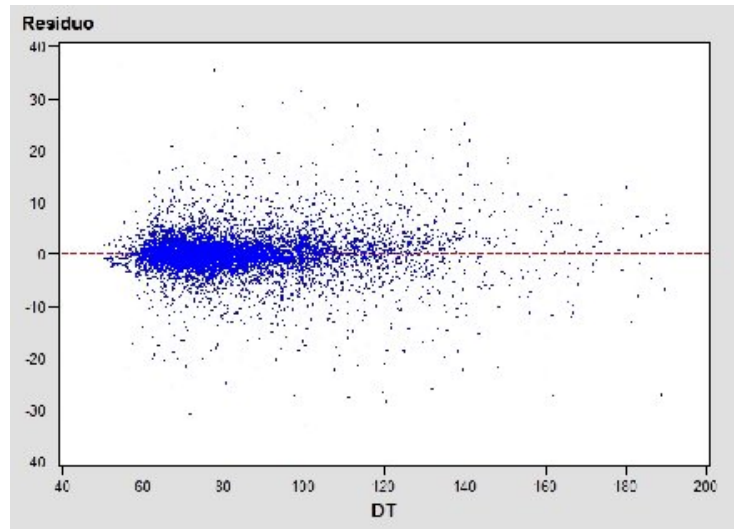

(c) P3

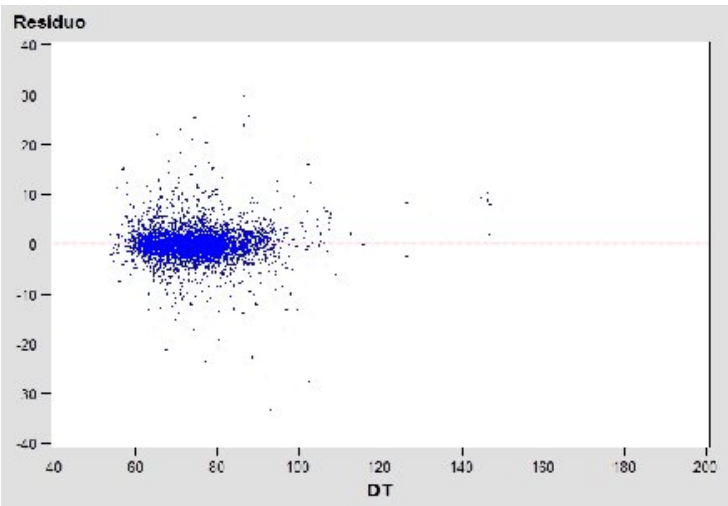

(b) P2

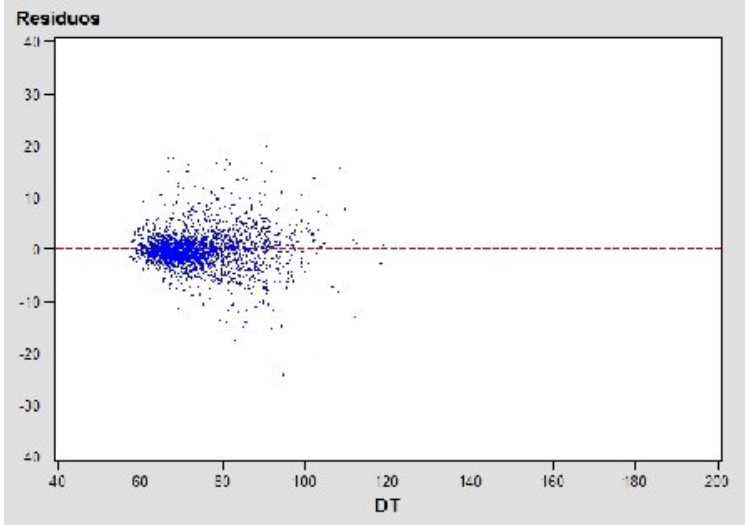

(d) P4

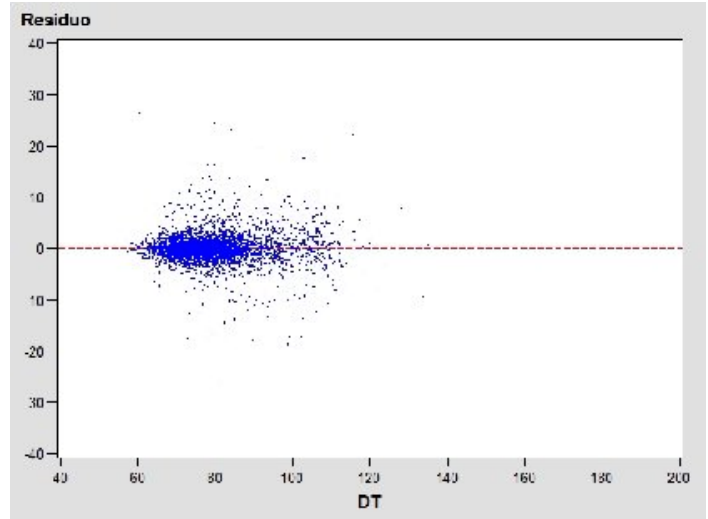

(e) 
Observa-se, na Figura 4 (a), que os resíduos estão mais concentrados no intervalo de 60 a 100 microssegundos por pé. O gráfico da Figura 3 (b) apresenta uma pequena falha, da profundidade de $1499,5 \mathrm{~m}$ a $1507,5 \mathrm{~m}$, isso se deve a um filtro realizado na variável Dcali para valores menores que 2,5 .

Analisando-se os resíduos ao longo da variável DT, nas Figuras 3 e 4, verifica-se que o modelo estudado está adequado, pois os resíduos concentram-se em torno da média zero.

\section{Conclusões}

Esse trabalho comparou a construção de modelos gerados de perfis sônicos sintéticos nos poços de petróleo perfurados nas unidades geológicas pertencentes a Bacia Sedimentar Sergipe Alagoas. Esses modelos permitem que geólogos e geofísicos obtenham informações que venham aumentar a qualidade e a confiabilidade dos perfis sônicos sintéticos gerados, dando subsídios do ponto de vista da sua adequabilidade para ser usado como informação geológica, nas interpretações e processamento geofísico, nas áreas cujos poços não dispõem do perfil sônico registrado.

Modelaram-se os poços através da regressão pelo método dos mínimos quadrados ordinários, onde os resultados em todos os poços apontaram um resíduo correlacionado, sendo necessária a aplicação de um método corretivo para a retirada da autocorrelação das variáveis. $\mathrm{O}$ método utilizado foi o processo iterativo de Cochrane-Orcutt, onde se obteve coeficientes estatisticamente significantes.

Com a aplicação do Teste $t$ de student e a análise dos respectivos p-valores nos poços de petróleo, observou-se que nos poços P1, P2 e P4 nem todos os coeficientes são significativos, ou seja, nem todas as variáveis analisadas possuem influencia na variável DT, tornando-se necessário a exclusão da variável Dcali para os poços P1 e P2 e a exclusão da variável GR para o poço P4.

Verificou-se após a retirada da autocorrelação das variáveis, que não obteve-se nenhum valor para o MAPE menor do que 2,65\%, que consiste num bom ajuste .

Levando em consideração a homogeneidade das variáveis dos poços, conclui-se que nos poços de petróleo, a variável RHOB se destaca como a mais homogênea, ou seja, o nível de dispersão das observações estão mais próximos, ao contrário da variável ILD que apresentou-se como a mais heterogênea. 


\begin{abstract}
The sonic profile is used, mainly in pioneering wells, that receive greaters investments for acquisition from data, therefore these wells serves as reference to analyze the petroliferous potential of the area. For considered wells of explotation, normally the sonic tools are not races because economic reasons, mainly in the times of price of low oil. As it is not viable economically to make an acquisition of the sonic profile, in the great majority of the old wells, mainly when stop of the production of the oil, it must be appealed to other ways to solve the problem. One in the ways is to use statistical methods that generate a sonic profile, said synthetic, to establish estimates of the seismic speeds of the rocks throughout the wells. Thus, this work aims to compare found models, using as repressor variable the DT variable and the explanation variable, the variables RHOB, GR., DCali, PROF of the synthetic sonic profiles in wells of oil in the geologic units of the Basin Sedimentary Sergipe-Alagoas and that they are inside of the necessary standards of quality. Software used was SAS ${ }^{\circledR}$ Enterprise Guide 4.
\end{abstract}

Key-words: synthetic sonic profile o; regression Multiple, cohrane-orcutt test

\title{
Referências
}

ANDERSON, D. R.; SWEENEY, D. J.; WILLIAMS, T. Statistics for business and economics. 3 ed, South-Western, 2002.

CHARNET, R.; BONVINO, H.; FREIRE, C. A. L.; CHARNET, E. M. R. Análise de modelos de regressão linear com aplicações. Campinas, SP: Unicamp, 1999.

GARDNER, G. H. F.; GARDNER, L. W; GREGORY, A. R. Formation velocity and density: the diagnostic basis for stratigraphics traps. Geophysics, SEG, Tulsa, vol XXXIX, pp - 770-780. 1974.

GUJARATI, D. N. Econometria básica. 3. ed.São Paulo: Makron Books, 2000.

HAIR, J. F.; ANDERSON, R. E.; TATHAM, R. L.; Análise Multivariada de Dados. 5 ed. Porto Alegre:Bookman 2005 .

HOFFMANN, R.; VIEIRA, S. Análise de Regressão: Uma Introdução à Econometria, HUCITEC, São Paulo. 1998

LEVINE, D. M.; BERENSON, M. L.; STEPHAN, D. Estatística; Teoria e Aplicações. Rio de Janeiro, LTC, 2000.

RAGSDAle, C. T. Spreadsheet Modeling and Decision Analysis. 3 ed, South-Western College Publishing, Cincinnati, Ohio, 2001.

SUBRAMANIAN, A.; COUTINHO, A. S.; SILVA, L. B. da S. Aplicação de método e técnica multivariados para previsão de variáveis termoambientais e perceptivas. Produção, v. 17, n. 1, p. 052-070, Jan./Abr. 2007

THOMAS, J. E. Fundamentos e Engenharia de Petróleo. PETROBRAS. Rio de Janeiro: Ed. Interciência, 2001

VASQUEZ, A. C. R. Recuperação de atributos sísmicos utilizando a migração para afastamento nulo. Campinas: Dissertação do Depto. de Eng. do Petróleo UNICAMP, 1999

WOOLDRIDGE, J. M. Introdução à econometria:uma abordagem moderna. São Paulo: Pioneira Thomson Learning. 2006.

\section{Dados dos autores:}

Nome completo: Suzana Leitão Russo

Filiação institucional: Universidade Federal de Sergipe

Departamento:Depto de Estatística e Ciências Atuariais

Função ou cargo ocupado: Professora 
Endereço completo para correspondência: Rua Josué de Carvalho Cunha 395 Coroa do Meio Aracaju - SE - 49035490

Telefones para contato: 55-79-32551636

e-mail: suzanarusso@ufs.br

Nome completo: Maria Emilia Camargo

Filiação institucional: Universidade de Caxias do Sul

Departamento: Programa de Mestrado em Administração

Função ou cargo ocupado: Professora

Endereço completo para correspondência: Av. João Machado Soares, 3199, Camobi, 97.110-000, Santa Maria - RS

Telefones para contato: 55-3226-1348

e-mail: kamargo@terra.com.br

Nome completo: Vitor Hugo Simon

Filiação institucional: PETROBRAS

Departamento: UN-SEAL/ENGP/CER

Função ou cargo ocupado: Geólogo Sênior - Consultor

Endereço completo para correspondência: Rua Silvio Cezar Leite, 301. Ap. 303. Salgado Filho. Aracaju SE. CEP: 49020-060

Telefones para contato:55-79-3212-2848

e-mail: vhsimo@petrobras.com.br 